\title{
Kriteria Lokasi Pembangunan Tower BTS (Base Transceiver System) di Kota Kediri
}

\author{
Rofiqoh Etika Amalin dan Ketut Dewi Martha Erli Handayeni \\ Jurusan Perencanaan Wilayah dan Kota, Fakultas Teknik Sipil dan Perencanaan, \\ Institut Teknologi Sepuluh Nopember (ITS) \\ Jl. Arief Rahman Hakim, Surabaya 60111 Indonesia \\ e-mail: erli.martha@gmail.com
}

\begin{abstract}
Abstrak - Infrastruktur telekomunikasi memiliki peran penting terhadap perkembangan ekonomi nasional. Menurut data Dirjen Pos dan Telekomunikasi pengguna seluler mengalami pertumbuhan rata-rata $31,9 \%$ pertahun dalam periode 20062010. Upaya untuk meningkatan layanan telekomunikasi di Kota Kediri memiliki masalah karena terdapat keberadaan menara yang mengganggu kenyamanan masyarakat sekitarnya, lokasi yang melanggar aturan dan tower BTS yang tidak memiliki ijin. Perspektif pemilihan lokasi dari pemerintah dan operator memiliki perbedaan, sedangkan infrastruktur tersebut harus berada di lokasi yang strategis untuk mendapatkan hasil yang optimal. Oleh sebab itu, perlu adanya penelitian untuk merumuskan kriteria lokasi menurut stakeholder di Kota Kediri. Metode yang digunakan yakni analisis Delphi untuk menentukan faktor penentu lokasi. Kemudian setelah ditemukan faktor dilakukan pembobotan terhadap faktor dengan analisis AHP. Analisis terakhir yakni perumusan kriteria dengan menggunakan Content Analysis. Dari analisis Delphi dihasilkan 20 faktor yang digunakan sebagai faktor penentu lokasi pembangunan tower BTS di Kota Kediri. Faktor tersebut yakni jarak terhadap konsumen, jumlah penduduk yang dilayani, luas jangkauan pelayanan, kualitas layanan, banyaknya permintaan, pertumbuhan penduduk, perilaku pelanggan, sikap masyarakat, banyaknya gedung tinggi, ketersediaan lahan, ruang udara, estetika lingkungan, berada dalam wilayah jangkauan sel, jarak dengan kegiatan sekitar, perencanaan tata ruang, biaya pajak, proses perijinan, terdapat akses jalan, biaya investasi, ketersediaan energi listrik. Dari masing-masing faktor tersebut, diperoleh 3 faktor dengan bobot tertinggi, yakni ketersediaan energi listrik $(0,09934)$, sesuai dengan rencana tata ruang (0.09646), dan proses perijinan (0.09194). Ketiga faktor ini paling besar pengaruhnya terhadap pemilihan lokasi tower BTS di Kota Kediri. Dengan demikian diperoleh kriteria utama lokasi pembangunan tower BTS di Kota Kediri adalah tersedianya energi listrik dengan daya yang memadai untuk BTS, lokasi yang harus sesuai dengan rencana tata ruang, dan lokasi yang memenuhi semua proses perizinan. Dari penelitian ini didapatkan bahwa energi listrik yang memadai menjadi prioritas untuk memilih lokasi tower BTS.
\end{abstract}

Kata Kunci-infrastruktur telekomunikasi, kriteria, lokasi tower BTS.

\section{PENDAHULUAN}

$I^{1}$ NFRASTRUKTUR telekomunikasi memiliki peran penting terhadap perkembangan ekonomi nasional [7]. Selain itu, permintaan terhadap layanan telekomunikasi semakin banyak didukung dengan adanya perkembangan teknologi dibidang telekomunikasi yang sangat berkembang pesat. Sehingga kebutuhan untuk berkomunikasi menjadi kebutuhan dasar bagi setiap manusia [6].

Dalam mendukung kegiatan berkomunikasi para operator terus membangun infrastruktur sebagai usaha coverage area pelayanannya semakin luas dan kualitasnya lebih baik. Salah satu infrastruktur yang terus menerus dibangun adalah Base Transceiver Station (BTS). Dalam pembangunan BTS terdapat beberapa permasalahan seperti tidak memiliki izin, tidak sesuai dengan rencana tata ruang, dan lokasi pembangunan berada di dekat dengan pemukiman. Permasalahan pembangunan BTS ini juga terdapat di Kota Kediri [3].

Jumlah tower BTS di Kota Kediri berjumlah 49 buah yang tersebar di 3 kecamatan [3]. Menara telekomunikasi di Kota Kediri memiliki masalah karena sebagian keberadaan menara tersebut mengganggu kenyamanan masyarakat sekitarnya dan tower BTS yang tidak memiliki ijin. Tower BTS yang tidak memiliki ijin ditindak dengan melakukan penyegelan terhadap tower tersebut oleh Satpol PP [4].

Tower BTS yang berdiri di Kelurahan Bandar Lor RT 06 RW 01 Kecamatan Mojoroto berada di dekat pasar dan dekat dengan pemukiman warga. Tower tersebut mendapatkan penolakan dari masyarakat sekitar. Hal ini disebabkan oleh pembangunan tower BTS tidak diketahui oleh masyarakat dan pembangunannya tidak memiliki izin. Menurut Sujono anggota Komisi A DPRD Kota Kediri yang dijelaskan dalam bangsaonline.com, persoalan dalam pengurusan IMB banyak terjadi disebabkan oleh pengusaha yang hanya menemui RT/RW setempat karena dengan berbagai alasan sehingga pengusaha enggan bertatap muka langsung dengan masyarakat sekitar. Perizinan dalam pembangunan tower yang bermasalah tidak hanya terjadi di Bandar Lor persoalan perizinan pembangunan. Jumlah tower BTS selain di Bandar Lor yang tidak memiliki ijin berjumlah 2 buah, pertama berada di selatan Masjid Agung Jl Panglima Sudirman dan kedua berada di Lingkungan Tirtoudan, Kelurahan Tosaren, Kecamatan Pesantren, Kota Kediri [1].

Rencana perkembangan infrastruktur telekomunikasi di Kota Kediri menurut RTRW Kota Kediri Tahun 2011-2030 yaitu dengan meningkatkan pelayanan telekomunikasi secara terestrial maupun sistem kabel ke seluruh kawasan permukiman dan kawasan fungsional kota lainya. Pengembangan sistem prasarana telekomunikasi dengan sistem seluler dilakukan dengan mengembangkan menara BTS sesuai kebutuhan dan jangkauan pelayanan. Sedangkan untuk peraturan zonasi 
jaringan telekomunikasi dikelola dengan memperhatikan pemanfaatan ruang untuk penempatan tower pemancar telekomunikasi dan memperhitungkan aspek keamanan serta keselamatan aktivitas kawasan disekitarnya. Demikian menurut perspektif dari pemerintah sebagai regulator.

Pembangunan tower BTS menurut perspektif dari pihak operator yakni dapat memberikan keuntungan bagi oeprator dalam hal mendapatkan coverage area yang lebih luas [2]. Oleh sebab itu dalam pembangunan BTS, operator mempertimbangkan penentuan lokasi. Lokasi BTS yang tepat dapat memaksimalkan jangkauan terhadap jangkauan cakupan wilayah dan pelayanan trafiknya [4].

Dalam memilih lokasi pembangunan memiliki dua sudut pandang yaitu sudut pandang dari pengusaha dan sudut pandang dari pemerintah. Pengusaha melihat lokasi dari sudut keuntungan maksimum untuk jangka panjang, namun dari pemerintah mempertimbangkan dari sudut efisiensi pemakaian ruang. Efisiensi yang dimaksud adalah memilih kegiatan yang paling cocok untuk lokasi tersebut agar menjamin keserasian pemakaian lahan yang secara nasional [8]. Untuk memudahkan proses perizinan, maka diperlukan adanya pertimbangan lokasi yang sesuai, baik menurut pemerintah, operator, maupun stakeholder lain yang berkaitan.

Pembangunan tower BTS memiliki manfaat bagi perkembangan daerah namun juga dapat menimbulkan dampak negative dan konflik di kemudian hari apabila terdapat ketidaksesuaian dalam pemilihan lokasi baik dari sisi perspektif regulator maupun operator. Oleh sebab itu dalam pembangunan tower BTS perlu diperhatikan kriteria lokasinya, agar manfaat yang didapatkan dari pembangunan tersebut lebih maksimal.

\section{METODE PENELITIAN}

\section{A. Jenis dan Pendekatan Penelitian}

Pendekatan yang digunakan dalam penelitian ini yakni pendekatan rasionalisme. Pendekatan rasionalisme adalah pendekatan yang menjadikan akal/rasio sumber sebagai dari segala kebenaran. Jenis penelitian yang digunakan yakni penelitian kualitatif dan kuantitatif. Data yang digunakan dalam penelitian ini merupakan data kualitatif yang diubah dalam bentuk kuantitatif. Data kualitatif ini digunakan untuk menentukan faktor dan kriteria yang mempengaruhi penentuan lokasi pembangunan tower BTS. Data kualitatif yang dikuantitatifkan adalah data yang didapat untuk menentukan bobot faktor yang digunakan untuk menentukan lokasi pembangunan tower BTS di Kota Kediri. Sedangkan deskriptif digunakan untuk menjelaskan tentang infrastruktur, BTS, dan penentuan lokasi sehingga didapatkan variabel-variabel yang digunakan dalam penelitian ini.

\section{B. Variabel Penelitian}

Tabel 1.

Variabel penelitian

\begin{tabular}{ll} 
& \multicolumn{1}{c}{ Variabel penelitian } \\
\hline \hline Indikator & \multicolumn{1}{c}{ Variabel } \\
\hline Jangkauan pelayanan & Range: jarak terhadap pasar (konsumen) \\
& Treshold: jumlah penduduk yang dilayani \\
& Luas jangkauan pelayanan \\
& Kualitas layanan \\
Permintaan & Banyaknya permintaan
\end{tabular}

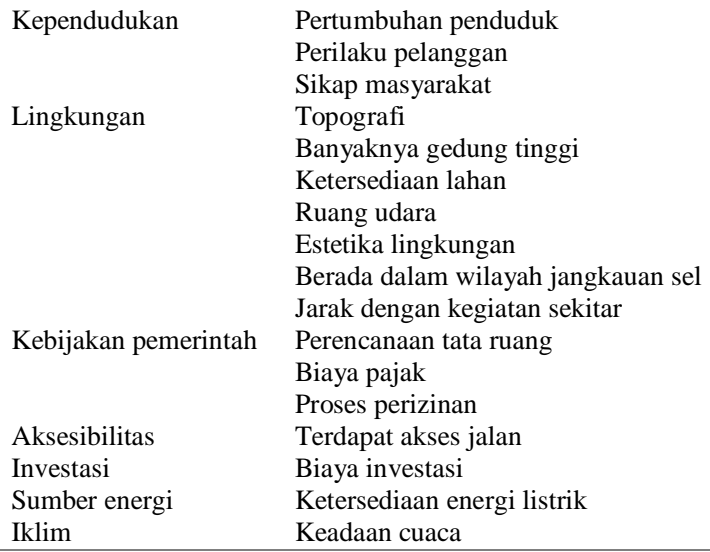

\section{Metode Pengumpulan Data}

Dalam melakukan pengumpulan data, dilakukan melalui survey primer. untuk mendapatkan fakta dan kondisi eksisting Kota Kediri dilakukan dengan survey sekunder menggunakan media internet dan dokumen dari instansi terkait. Survey primer dilakukan untuk mendapatkan data yang dibutuhkan untuk analisis. data tersebut didapatkan dengan cara wawancara dan kuesioner kepada pihak terkait pembangunan tower BTS.

\section{Metode Analisis}

\section{1) Teknik Delphi untuk menentukan faktor-faktor penentu lokasi pembangunan Tower BTS di Kota Kediri}

Dalam menentukan faktor, dilakukan dengan menggunakan metode analisis delphi. Metode delphi adalah metode digunakan untuk mengumpulkan pendapat dari responden serta membuat kesepakatan dalam mengambil keputusan kelompok. Responden disini dipilih dengan teknik stakeholder analisis. Sehingga responden tersebut memiliki kepentingan dan pengetahuan mengenai pembangunan tower BTS. Dengan menggunakan metode delphi membuat para ahli dapat menyepakati keputusan secara sistematis dengan permasalahan yang sangat kompleks. media yang digunakan untuk melakukan metode ini adalah dengan menyebarkan kuesioner. Kuesioner tersebut dibentuk dengan tujuan agar respon individu terhadap sebuah permasalahan yang diteliti dapat berkembang.

2) AHP untuk menentukan bobot faktor-faktor penentu lokasi pembangunan Tower BTS di Kota Kediri

Untuk menentukan bobot masing-masing faktor dilakukan dengan menggunakan metode AHP. Pendapat bobot dari masing-masing responden didapatkan dengan menggunakan kuesioner.

3) Content Analysis untuk merumuskan kriteria faktorfaktor penentu lokasi pembangunan Tower BTS di Kota Kediri

Merumuskan kriteria lokasi ini dilakukan dengan menggunakan teknik analisis konten. Content analysis adalah penelitian yang bersifat pembahasan mendalam terhadap isi suatu informasi tertulis atau tercetak dalam media massa. Metode content analysis adalah suatu teknik yang digunakan untuk mengambil kesimpulan dengan mengidentifikasi karakteristik khusus suatu pesan secara objektif sehingga kesimpulan yang dihasilkaan akan sama walaupun berbeda peneliti, sistematis sehingga penetapan isi atau kategori dilakukan menurut aturan yang diterapkan secara konsisten, 
dan generalis yakni penemuan harus memiliki referensi yang teoritis.

\section{HASIL DAN DISKUSI}

\section{A. Faktor-Faktor Penentu Lokasi Pembangunan Tower BTS di Kota Kediri}

Untuk menentukan faktor penentu lokasi pembangunan tower BTS di Kota Kediri dilakukan dengan menggunakan teknik analisis delphi. Responden dalam analisis delphi ini yakni Bappeda Bidang Fisik dan Prasarana, PU Bidang Tata Ruang, Dishubkominfo Bidang Kominfo, Operator, Akademisi Tata Ruang, dan Akademisi Elektro. Responden dipilih dengan menggunakan stakeholder analisis.

Dari eksplorasi pendapat dari stakeholder mengenai faktor pemilihan lokasi tower BTS pada delphi I, didapatkan 12 faktor yang sudah konsensus meliputi kualitas layanan, pertumbuhan penduduk, sikap masyarakat, ketersediaan lahan, ruang udara, estetika lingkungan, berada dalam wilayah jangkauan sel, range: jarak terhadap pasar (konsumen), sesuai dengan perencanaan tata ruang, proses perijinan, terdapat akses jalan, dan ketersediaan energi listrik. Sedangkan 10 faktor lainnya belum konsensus.

Dari analisis Delphi tahap 2 dihasilkan 6 faktor yang telah konsensus, yakni faktor luas jangkauan pelayanan, topografi, banyaknya gedung tinggi, biaya pajak, biaya investasi, dan keadaan cuaca. Sedangkan 4 faktor lainnya belum konsensus.

Pada wawancara Delphi untuk yang ketiga kalinya, variabel sudah mencapai konsensus dari semua responden. Oleh karena itu, proses iterasi dihentikan. Dari hasil iterasi Delphi di atas, didapatkan faktor penentu lokasi pembangunan tower BTS di Kota Kediri.

Tabel 2.

Faktor penentu lokasi pembnagunan tower BTS di Kota Kediri

\begin{tabular}{ll}
\hline No & \multicolumn{1}{c}{ Faktor } \\
\hline 1 & Range: jarak terhadap pasar (konsumen) \\
2 & Treshold: jumlah penduduk yang dilayani \\
3 & Luas jangkauan pelayanan \\
4 & Kualitas layanan \\
5 & Banyaknya permintaan \\
6 & Pertumbuhan penduduk \\
7 & Perilaku pelanggan \\
8 & Sikap masyarakat \\
9 & Banyaknya gedung tinggi \\
10 & Ketersediaan lahan \\
11 & Ruang udara \\
12 & Estetika lingkungan \\
13 & Berada dalam wilayah jangkauan sel \\
14 & Jarak dengan kegiatan sekitar \\
15 & Sesuai dengan perencanaan tata ruang \\
16 & Biaya pajak \\
17 & Proses perijinan \\
18 & Terdapat akses jalan \\
19 & Biaya investasi \\
20 & Ketersediaan energi listrik \\
\hline \hline
\end{tabular}

Berdasarkan hasil wawancara melalui teknik Delphi diperoleh bahwa terdapat 20 variabel yang perlu diperhitungkan sebagai faktor lokasi penentu pembangunan tower BTS di Kota Kediri.

\section{B. Bobot Faktor-Faktor Penentu Lokasi Pembangunan Tower BTS di Kota Kediri}

Dalam menentukan bobot masing-masing faktor dalam penentuan lokasi pembangunan tower BTS dilakukan dengan menggunakan teknik analisis AHP. Dalam analisis ini, stakeholder membandingkan dengan cara memberikan bobot pada faktor-faktor yang sudah didapatkan pada tahap sebelumnya.

Hasil analisis AHP menunjukkan bahwa bobot tertinggi adalah faktor ketersediaan energi listrik $(0,09934)$, sedangkan bobot terendah adalah faktor pertumbuhan penduduk (0.02391) dengan inconsistensi nilai 0,04064. pada tabel dibawah ini adalah nilai bobot faktor lokasi BTS dari tertinggi hingga terendah.

Tabel 3.

\begin{tabular}{clc} 
Bobot faktor penentu lokasi pembangunan tower BTS di Kota Kediri \\
\hline \hline No & \multicolumn{1}{c}{ Faktor } & Bobot \\
\hline 1 & Ketersediaan energi listrik & 0,09934 \\
2 & Sesuai dengan perencanaan tata ruang & 0,09646 \\
3 & Proses perijinan & 0,09194 \\
4 & Terdapat akses jalan & 0,06905 \\
5 & Biaya investasi & 0,06481 \\
6 & Kualitas layanan & 0,06408 \\
7 & Berada dalam wilayah jangkauan sel & 0,06300 \\
8 & Biaya pajak & 0,05570 \\
9 & Estetika lingkungan & 0,05324 \\
10 & Banyaknya permintaan & 0,04148 \\
11 & Ruang udara & 0,04102 \\
12 & Treshold: jumlah penduduk yang dilayani & 0,03396 \\
13 & Jarak dengan kegiatan sekitar & 0,03122 \\
14 & Ketersediaan lahan & 0,03114 \\
15 & Luas jangkauan pelayanan & 0,03038 \\
16 & Perilaku pelanggan & 0,03012 \\
17 & Range: jarak terhadap pasar (konsumen) & 0,02824 \\
18 & Banyaknya gedung tinggi & 0,02637 \\
19 & Sikap masyarakat & 0,02452 \\
20 & Pertumbuhan penduduk & 0,02391 \\
\hline \hline
\end{tabular}

Bobot faktor ketersediaan energi listrik mendapat nilai tertinggi karena merupakan faktor yang penting untuk membuat mesin dari BTS bekerja. Sehingga listrik menjadi faktor yang penting. Kemudan bobot faktor terendah adalah pertumbuhan penduduk. Hal ini disebabkan oleh pembangunan tower BTS harus memperhitungkan pertumbuhan penduduk lokasi tersebut, namun lokasi pembangunan tower BTS bisa dipilih karena terdapat permintaan dari pemerintah setempat karena kekurangan layanan telekomunikasi.

\section{Kriteria Faktor-Faktor Penentu Lokasi Pembangunan Tower BTS di Kota Kediri}

Dalam menentukan kriteria lokasi untuk pembangunan tower BTS di Kota Kediri dilakukan dengan menggunakan Content Analysis. Dalam melakukan Content Analysis, Software yang digunakan untuk mengolah data transkrip tersebut adalah software NVivo 11 Student. Hasil Content Analysis dapat dilihat pada tabel dibawah ini.

Tabel 4.

Kriteria faktor penentu lokasi pembangunan tower BTS di Kota Kediri

\begin{tabular}{cll}
\hline \hline No & \multicolumn{1}{c}{ Faktor } & \multicolumn{1}{c}{ Kriteria } \\
\hline 1 & $\begin{array}{l}\text { Ketersediaan energi } \\
\text { listrik }\end{array}$ & $\begin{array}{l}\text { Tersedia energi listrik dengan daya yang } \\
\text { memadai untuk BTS. }\end{array}$
\end{tabular}


2 Sesuai dengan perencanaan tata ruang

3 Proses perijinan

4 Terdapat akses jalan

$5 \quad$ Biaya investasi

6 Kualitas layanan

7 Berada dalam wilayah jangkauan sel

8 Biaya pajak

9 Estetika lingkungan

10 Banyaknya permintaan

11 Ruang udara

12 Treshold: jumlah penduduk yang dilayani

13 Jarak dengan kegiatan sekitar

14 Ketersediaan lahan

15 Luas jangkauan pelayanan

16 Perilaku pelanggan

17 Range: jarak terhadap pasar (konsumen)

18 Banyaknya gedung tinggi

19 Sikap masyarakat

20 Pertumbuhan penduduk

\section{KESIMPULAN}

Dalam pembangunan tower BTS diharapkan bahwa terdapat persepsi yang sama antar stakeholder. Dari analisis yang dilakukan dalam penelitian ini, didapatkan 20 faktor konsensus yang mempengaruhi pemilihan lokasi pembangunan tower BTS di Kota Kediri. Faktor-faktor tersebut adalah jarak terhadap konsumen, jumlah penduduk yang dilayani, luas jangkauan pelayanan, kualitas layanan, banyaknya permintaan, pertumbuhan penduduk, perilaku pelanggan, sikap masyarakat, banyaknya gedung tinggi, ketersediaan lahan, ruang udara, estetika lingkungan, berada dalam wilayah jangkauan sel, jarak dengan kegiatan sekitar, perencanaan tata ruang, biaya pajak, proses perizinan, terdapat akses jalan, biaya investasi, serta ketersediaan energi listrik.

Faktor yang telah dipilih sebagai faktor penentu lokasi pembangunan tower BTS memiliki bobot masing-masing. Tiga faktor dengan bobot tertinggi adalah ketersediaan energi listrik, perencanaan tata ruang, dan proses perizinan. Ketiga faktor ini paling besar pengaruhnya dalam pemilihan lokasi pembangunan tower BTS di Kota Kediri.
Berdasarkan ketiga faktor penentu lokasi tower BTS tersebut, maka dihasilkan kriteria utama lokasi BTS di Kota Kediri yaitu:

1. Tersedia energi listrik dengan daya yang memadai untuk BTS.

2. Lokasi yang harus sesuai dengan rencana tata ruang.

3. Lokasi yang memenuhi semua proses perizinan, baik izin masyarakat, izin lingkungan, maupun izin lokasi.

Dari penelitian ini didapatkan bahwa energi listrik yang memadai menjadi prioritas untuk memilih lokasi tower BTS. Pada kondisi eksisting, ketersediaan energi listrik yang paling tinggi terdapat di Kecamatan Pesantren. Sementara lokasi BTS yang tidak memiliki izin berada di Kecamatan tersebut. Sehingga, prioritas penentuan lokasi pembangunan tower BTS adalah mempertimbangkan ketersediaan listrik yang memadai.

\section{DAFTAR PUSTAKA}

[1] Bangsaonline. (2015). Retrieved Februari 20, 2016, from Diduga tak Berijin, Warga Bandar Lor Kota Kediri Wadul Dewan atas Pendirian Menara BTS: http://www.bangsaonline.com/berita/16159/diduga-takberijin-warga-bandar-lor-kota-kediri-wadul-dewan-atas-pendirianmenara-bts

[2] CME, T. (2012). Manfaat Tower bagi semua pihak. Retrieved Februari 20, 2016, from Citra Megah Elektrik Jasa Kontruksi dan Mekanikel: http://cmeteam86.blogspot.co.id/p/manfaat-tower-bagi-semuapihak.html

[3] Depkominfo. (2010). Studi Dampak Penataan Lokasi Menara BTS Terhadap Kualitas Layanan Jaringan Bergerak Seluler. Jakarta: Puslitbang Pos dan Telekomunikasi.

[4] Fachrie, M., Widowati, S., \& Hanuranto, A. T. (2012). Implementasi Fuzzy Evolutionary Algorithms untuk Penentuan Posisi Base Transceiver Station (BTS). Seminar Nasional Aplikasi Teknologi Informasi 2012. Yogyakarta.

[5] Mashudi, D. (2014, September 14). Satpol PP Kota Kediri Segel Menara Tower Ilegal. Retrieved Februari 20, 2016, from Suryaonline: http://surabaya.tribunnews.com/2014/09/04/satpol-pp-kota-kediri-segelmenara-tower-ilegal

[6] Payung, R. R. (2015, September 03). Dampak Perkembangan Infrastruktur Media dan Telekomunikasi di Masyarakat. Retrieved Februari 17, 2016, from Institut Komunikasi Indonesia Baru: http://komunikasi.us/index.php/course/5176-dampak-perkembanganinfrastruktur-media-dan-telekomunikasi-di-masyarakat

[7] PT Telkom Indonesia, T. (2009). Tinjauan Industri Telekomunikasi di Indonesia.

[8] Tarigan, R. (2004). Ekonomi Regional: Teori dan Aplikasi. Jakarta: Bumi Aksara. 